\title{
Irrational Orientations and Atomistics at Gold-Rutile Interfaces
}

Minghui Lin, Yushun Liu and Guo-zhen Zhu

University of Manitoba, Winnipeg, Manitoba, Canada

Oxide-supported metal nanoparticles have been extensively investigated as an active catalyst for many chemical reactions, especially the interactions between metals and oxides at the interface [1]. Recently, the interface structure of two lattice-matched systems, i.e., $\mathrm{Au}-\mathrm{MgAl}_{2} \mathrm{O}_{4}$ and $\mathrm{Au}-\mathrm{SrTiO}_{3}$, were reported with interfacial reconstructions as a result of energy minimization [2-4]. However, metal-oxide interfaces with a large lattice mismatch, e.g. $\mathrm{Au}-\mathrm{TiO}_{2}$, are less understood in terms of the orientation relationships (ORs), atomic arrangement, and electronic structure of the interface. Furthermore, sample preparation history has a considerable influence on $\mathrm{Au}-\mathrm{TiO}_{2}$ interface, resulting in discrepancies in crystallographic orientations and atomistic in the literature [5].

In this work, we performed a systematic study on $\mathrm{Au}_{-}-\mathrm{TiO}_{2}$ (rutile) interfaces using a model system of $\mathrm{Au}$ nanoparticles on $\mathrm{TiO}_{2}$ single-crystal substrates. In detail, gold films with a thickness of 5-10 nm were sputtered on single-crystal (110) rutile substrates (MTI Corporation), followed by heat treatment at 600$1000{ }^{\circ} \mathrm{C}$ for 10 mins in tube furnace within argon (99.9\% purity) atmosphere. The crystallography was analyzed with X-ray diffraction (XRD, Bruker Discover diffractometer). The morphology of samples was examined with scanning electron microscope (SEM, Tescan Mira3). Focus ion beam (FIB, FEI Versa 3D and GAIA3 GMU Model 2016) was used to prepare TEM specimens. The detailed interfaces were examined using transmission electron microscopy (TEM, JEOL-ARM200F and FEI-Titan 80-300 HB).

Fig.1(a) presents the morphology of gold nanoparticles after heat treatment at elevated temperature (e.g. $800{ }^{\circ} \mathrm{C}$ for $10 \mathrm{mins}$ ), where gold films broke up to nanoscale particles with faceted shape. As shown in the high angle angular dark field (HAADF) image in Fig.1(b), these particles exhibit a Wulff shape with intricated bases $<30 \mathrm{~nm}$ in height observed underneath, the contrast of which is close to the rutile substrates. The growth of such oxide bases have also been reported in other gold-oxide systems such as $\mathrm{Au}-\mathrm{MgAl} 2 \mathrm{O}_{4}$ and $\mathrm{Au}-\mathrm{SrTiO}_{3}$, likely associated with interface reconstruction.

The ORs between gold nanoparticles and rutile substrates were determined by combining XRD experiment and geometrical model of interface where lattice match between two crystallographic planes were calculated. All possible ORs can be indexed including four previously reported ones (ORa-ORd) and three new irrational ORs (ORe-ORg) as follows: ORa, $\left\{\begin{array}{lll}1 & 1 & 1\end{array}\right\}_{\mathrm{Au}} / /\left[\begin{array}{lll}1 & 1 & 0\end{array}\right\}_{\mathrm{TiO} 2},<\begin{array}{lll}-1 & 0\end{array}>_{\mathrm{Au}} / /\left[\begin{array}{lll}0 & 0 & 1\end{array}\right]_{\mathrm{TiO} 2}$ ; ORb, $\left\{\begin{array}{lll}1 & 1 & 2\end{array}\right\}_{\mathrm{Au}} / /\left\{\begin{array}{lll}1 & 1 & 0\end{array}\right\}_{\mathrm{TiO} 2},<\begin{array}{lll}1 & -1 & 0\end{array}>_{\mathrm{Au}} / /\left[\begin{array}{lll}0 & 0 & 1\end{array}\right]_{\mathrm{TiO} 2} ; \mathrm{ORc},\left\{\begin{array}{lll}0 & 0 & 1\end{array}\right\}_{\mathrm{Au}} / /\left\{\begin{array}{lll}1 & 1 & 0\end{array}\right\}_{\mathrm{TiO} 2},<\begin{array}{lll}1 & -1 & 0\end{array}>_{\mathrm{Au}} / /$ $\left[\begin{array}{lll}0 & 0 & 1\end{array}\right]_{\mathrm{TiO} 2}$; ORd, $\left\{\begin{array}{lll}1 & 1 & 0\end{array}\right\}_{\mathrm{Au}} / /\left\{\begin{array}{lll}1 & 1 & 0\end{array}\right\}_{\mathrm{TiO} 2},<\begin{array}{lll}1 & -1 & 0\end{array}>_{\mathrm{Au}} / /\left[\begin{array}{lll}0 & 0 & 1\end{array}\right]_{\mathrm{TiO} 2} ; \mathrm{ORe},\left\{\begin{array}{lll}1 & 1 & 4-3 \sqrt{2}\end{array}\right\} \mathrm{Au} / /\left\{\begin{array}{lll}1 & 1 & 0\end{array}\right\}_{\mathrm{TiO} 2}$,

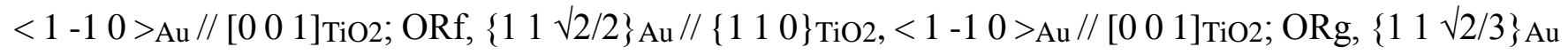
$/ /\left\{\begin{array}{lll}1 & 1 & 0\end{array}\right\}_{\mathrm{TiO} 2},<\begin{array}{lll}1 & -1 & 0\end{array}>\mathrm{Au} / /\left[\begin{array}{lll}0 & 0 & 1\end{array}\right] \mathrm{TiO} 2$. The atomic structure of gold-rutile interfaces with ORa, ORb, ORe, and ORf was further investigated with STEM-HAADF imaging as shown in Fig.2. Viewed along direction, ORa is commonly reported in the literature with a relatively flat interfacial atomic layer that mixes gold and rutile lattices [5]. In contrast, ORe and ORf have zig-zag interfaces consisting of alternating low-index crystallographic planes. As for ORb, the atomic arrangement at the interface is different from either gold or rutile lattice, forming a transition layer less than $2 \mathrm{~nm}$ in thickness. Although further investigation is needed to extract more information at the interface, the appearance of this rough interface indicates the possibility of tailoring gold-rutile interface at high temperatures [6]. 

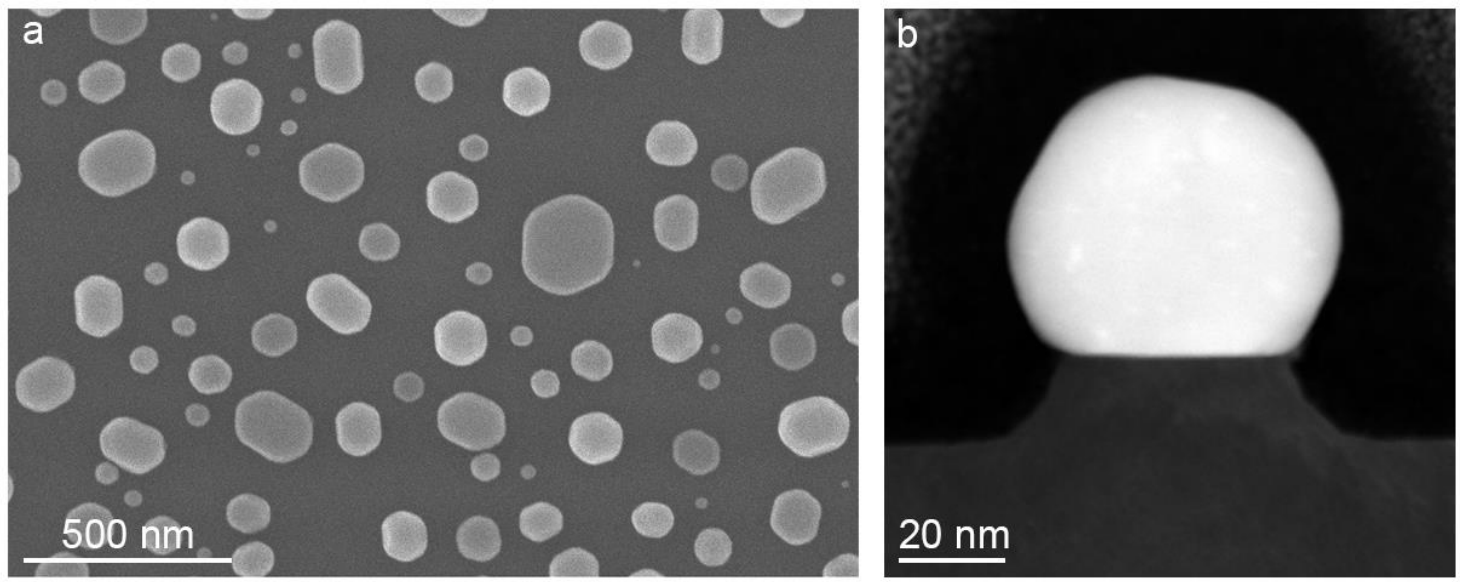

Figure 1. (a) SEM micrograph of dewetted gold nanoparticles on rutile substrate after being heat treated at $800{ }^{\circ} \mathrm{C}$ for 10 mins. (b) STEM-HAADF micrograph of representative gold particle.
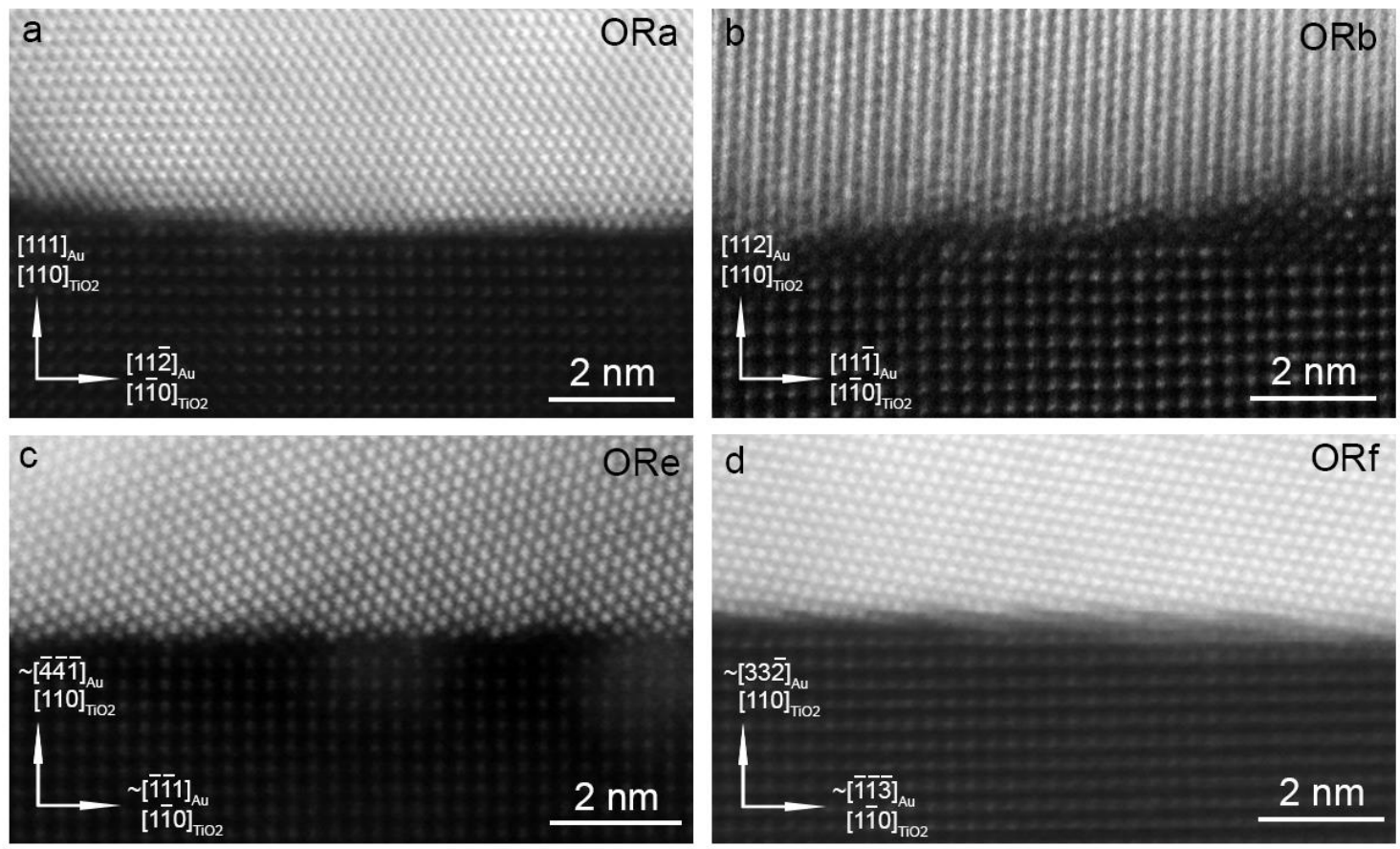

Figure 2. (a-d) STEM-HAADF micrographs of atomistic at gold-rutile interface corresponding to ORa, $\mathrm{ORb}, \mathrm{ORe}, \mathrm{ORf}$ respectively.

\section{References}

[1] M. Valden, X. Lai, D.W. Goodman, Science 281 (1998), pp. 1647-1650.

[2] T. Majdi et al., Appl. Phys. Lett. 107 (2015), p.241601.

[3] F. Liu et al., Adv. Mater. Interfaces 5 (2018), p.1701664.

[4] A. Yi et al., Mater. Charact. 151 (2019), pp.237-241.

[5] F. Cosandey, Philos. Mag. 93 (2013), pp.1197-1218.

[6] The authors acknowledge funding from the University of Manitoba and Canada Research Chair Program. 